\title{
Mechanical Properties of Polylactide Matrix Composite Reinforced with Long Maize Stalk Fibers
}

\author{
Daniel Łączny ${ }^{1 *}$, Marek Macko' ${ }^{1}$, Krzysztof Moraczewski ${ }^{2}$ \\ 1 Faculty of Mechatronics, Kazimierz Wielki University, ul. Chodkiewicza 30, 85-064 Bydgoszcz, Poland \\ 2 Institute of Materials Science and Engineering, Uniwersytet Kazimierza Wielkiego, ul. Chodkiewicza 30, \\ 85-064 Bydgoszcz, Poland \\ * Corresponding author's e-mail: daniel.I@ukw.edu.pl
}

\begin{abstract}
The aim of presented study was to investigate the effect of using long rotation maize stalk fibers as filler on the mechanical and thermomechanical properties of an injection molded biocomposite with a polylactide matrix using different fiber percentages. To evaluate the effect of maize stalk particle reinforcement on the PLA matrix, the mechanical properties of the biocomposites including tensile strength, tensile modulus, relative strain at maximum stress, strain at break, stress at break and Charpy unnotched impact strength were determined. From a mechanical point of view, the best fiber content was at $15 \%$ as it caused the least reduction in strain at break, stress at break, and strain at maximum stress relative to the polylactide matrix.
\end{abstract}

Keywords: polylactide, biocomposites, maize stalk, mechanical properties.

\section{INTRODUCTION}

Over the past 70 years, there has been a noticeable dynamic growth in the production of plastics worldwide. When only 1.5 million tons of plastics were produced in 1950, their production has already reached 367 million tons in 2019 [1]. The growing popularity of such materials is due to their low density, low price, ease of processing, high durability, good chemical resistance and good mechanical properties. Plastics have been used in a huge range of products and applications, particularly in the packaging, construction and automotive industries. Nowadays many products made of macromolecular plastics especially food packaging, clothing, household appliances save energy, reduce $\mathrm{CO}_{2}$ emission, water and food consumption. They play an important role in the development of modern society [2].

In 2015 , about $99 \%$ of polymer plastics were petroleum-based [3]. Each year, $6 \%$ of extracted crude oil is used to produce them. Oil consumption for plastics production is expected to increase to $20 \%$ of annual oil production by 2050 [4]. Therefore, the biopolymer industry is growing, using biomass as an alternative raw material to produce plastics. This is a promising solution that does not deplete fossil fuel reserves [5].

The high durability and good chemical resistance of most of the polymeric plastics are advantages of their functional properties. However, this poses a threat to the environment due to their resistance to natural degradation. Therefore, waste management of these materials has become a major challenge in many countries especially in the area of sustainable development. Currently, there are many places on earth where there are large amounts of polymeric plastic waste found in the natural environment especially in oceans and seas [6].

One of the ways to solve the problem of polymer waste is to use biodegradable plastics which are decomposed in the environment by microorganisms such as fungi, algae, bacteria etc. The biological degradation of plastics takes from a few to several weeks. During biodegradation, polymer chains decompose into $\mathrm{H}_{2} \mathrm{O}, \mathrm{CO}_{2}$ and biomass [7]. 
Degradation time depends on the type of plastic and the interaction of moisture, temperature, $\mathrm{pH}$, salinity, presence or absence of oxygen, UV light and/or enzymes that cause shortening and weakening of polymer chains $[8,9]$.

Biodegradable polymer plastics are obtained from natural and synthetic sources. From synthetic sources, biodegradable polymers are produced typically from petrochemical feedstocks such as polycaprolactone [10]. Biodegradable polymers made from natural raw materials are referred to as bioplastics. The raw material for their production is usually starch, cellulose, lignin and bioethanol. This group includes poly(3-hydroxybutyrate-co3-hydroxyvalerate) (PHBV), polyhydroxybutyrate (PHB) and polyhydroxyalkanoate (PHA), and polylactide (PLA) [11, 12].

Among the above bioplastics, polylactide is currently the most widely used [13]. The PLA is an aliphatic polyester and is made by ring-opening polymerization of lactide or by polycondensation of lactic acid. In the second method, the polymer has a lower molecular weight but is more commonly used in industrial production. Lactic acid, from which lactide is also derived, is produced from natural polysaccharides by fermentation of starch-rich biomass (potatoes or maize) [14, 15]. The PLA is a thermoplastic material, which can be processed by extrusion including blow molding, thermoforming and injection molding [16]. This polymer is biodegradable over a period of several months to 2 years. It has good tensile and compressive strength but has low ductility of less than $10 \%$ elongation at break. It is relatively brittle and has poor impact strength as well as poor gas and moisture barrier properties [17]. The PLA has no reactive side groups, and therefore is chemically inert and hydrophobic in nature [18]. Poor ductility and brittleness preclude PLA in applications where the material is plastically deformed at high stress levels. It is mainly used as a packaging material for products with short shelf life, including food and beverages [19]. It is also used in the biomedical industry in drug delivery systems, implants and tissue scaffolds [20].

The PLA relative to the most commonly used synthetic polymers (PE, PP, PET, PVC) is several times more expensive. In many consumer applications, higher strength and/or lower unit price of material is required. Therefore, for reinforcement purposes, natural fibers from plants commonly grown around the world are often used as fillers for PLA [21]. Plant fibers used in polymer composites can be extracted either from plants grown for textile purposes (jute, sisal, hemp, bamboo) or from by-products of agricultural production or food processing (straw, stalks, cobs, husks, shells, bran, etc.). From by-products, cellulosic fibers have a $90 \%$ lower manufacturing cost [22]. Composites consisting of biodegradable polymers and natural plant fibers are referred to as green composites [24]. These materials are entirely decomposed by microorganisms ultimately leaving only carbon dioxide and water as byproducts. The type of plant fiber, amount of fiber in the composite, fiber size, and fiber shape affect the final properties of green composite [25].

The aim of this study was to investigate the effect of using long rotation maize stalk fibers as filler on the mechanical and thermomechanical properties of an injection molded biocomposite with a polylactide matrix using different fiber percentages. To evaluate the effect of maize stalk particle reinforcement on the PLA matrix, the mechanical properties of the biocomposites including tensile strength, tensile modulus, relative strain at maximum stress, strain at break, stress at break and Charpy unnotched impact strength were determined.

The paper presents preliminary studies for fundamental research aimed at developing parameters of shredding process of maize stalks in multi-edge systems from the point of view of obtaining the most favorable selected properties of polymer composite.

\section{MATERIALS}

The composite materials were prepared from a polylactide (PLA) matrix reinforced with maize straw (CS) stalk fibers. The polylactide (3251 D) was supplied by NatureWorks (Minnetonka, U.S.). According to the manufacturer, the polylactide with a density of $1.24 \mathrm{~g} / \mathrm{cm}^{3}$, a glass transition temperature of 55 to $65^{\circ} \mathrm{C}$, and a melt mass flow rate $\left(190{ }^{\circ} \mathrm{C} / 2.16 \mathrm{~kg}\right)$ of $35 \mathrm{~g} / 10$ min is intended for injection molding applications. The maize stalks were hand harvested (Mogilno, Poland) and were dried for a period of 60 days at $18{ }^{\circ} \mathrm{C}$. After the drying period, they were shredded on a multi-hole, multi-edge system, which was equipped with two discs with different shapes of cutting surfaces. The shape of discs is shown in Figure 1. The movable disc operated at a rotational speed of $2050 \mathrm{rpm}$.

The different fiber lengths were separated using a Fritsch Anlysette 3 Pro sieve analyzer (Idar-Oberstein, Germany) equipped with a RETSCH DIN-ISO 


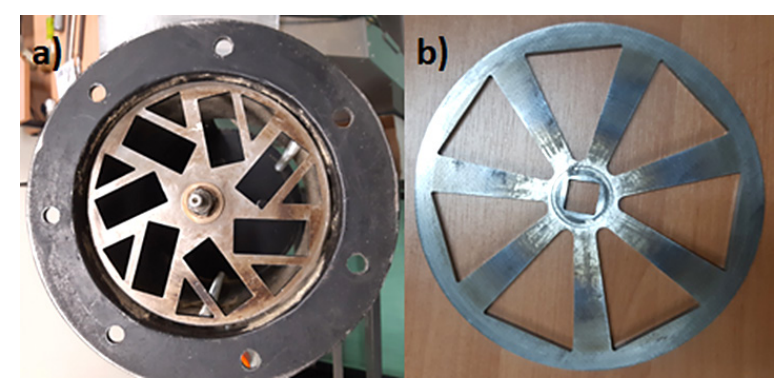

Fig. 1. Shredding system: a) fixed disc, b) movable disc

3310/1 measuring sieve set. The material was sieved for a period of 10 minutes with an amplitude of 2.5 $\mathrm{Hz}$ according to DIN 66165. Fiber lengths ranging from $4 \mathrm{~mm}, 2 \mathrm{~mm}, 1.6 \mathrm{~mm}$, and $1 \mathrm{~mm}$ were used to produce the composite, which were $20.5 \%, 32 \%$, $18 \%$, and $29.5 \%$, respectively. The fibers had an elongated needle-like shape. The average moisture content of fibers determined using a Radwag MA 110.R scale (Radom, Poland) was $9.5 \%$.

\section{METHODS}

\section{Extrusion}

Shredded maize stalks and PLA granules were dried in a Wamed laboratory dryer type SUP-100 (Warsaw, Poland) at $40{ }^{\circ} \mathrm{C}$ for 48 hours to remove residual moisture. The materials were then weighed separately using a Radwag WAS 160/X analytical balance (Radom, Poland). Composite formulations with 10,15 and $20 \mathrm{wt} \%$ filler content were prepared and designated PLA/CS10, PLA/CS15 and PLA/CS20, respectively.

The composite formulations were mixed manually and then poured into the hopper of a Metalchem single-screw extruder type W25-30D (Gliwice, Poland). The plastifying system of the extruder has one screw with a diameter of $25 \mathrm{~mm}$ (D) and a length to diameter ratio (L/D) of 30 . A sample containing pure PLA was prepared under identical conditions as the composite formulations. Temperature in the plastifying system of the extruder was $170{ }^{\circ} \mathrm{C}$ in the 1 st section, $175^{\circ} \mathrm{C}$ in the 2 nd section, $175^{\circ} \mathrm{C}$ in the $3 \mathrm{rd}$ section and $175^{\circ} \mathrm{C}$ on the nozzle, respectively, and was established on the basis of previous studies in which, among others, the thermal stability temperatures of natural fibers used were determined [26]. The rotational speed was set at $92 \mathrm{rpm}$. The extruded strands were cooled with compressed air and cut into granules using a knife granulator.

\section{Injection molding}

The granules obtained from extrusion to reduce moisture content were dried at $40{ }^{\circ} \mathrm{C}$ for 72 hours and then processed by injection molding in a TRX 80 Eco from Tederic (Shanchai, China). The temperature of the injection molding plastifying system from the feed section to the injection nozzle was $170-170-175-180{ }^{\circ} \mathrm{C}$. The short circuit force was $600 \mathrm{kN}$. After the material was injected into the mold, the samples were cooled for 60 seconds at $35{ }^{\circ} \mathrm{C}$. The resulting samples had the shape of a dog bone and their nominal dimensions were 80 $\mathrm{mm}$ long, $10 \mathrm{~mm}$ wide and $4 \mathrm{~mm}$ thick.

\section{Mechanical test}

For mechanical testing, six samples from each composition were used for each test. The results of mechanical tests are the results obtained from the arithmetic mean of each parameter along with the calculated standard deviation values.

Static tensile tests of PLA and PLA/CS samples were carried out on an Instron model 3367 universal testing machine (Norwood, U.S.). The tensile rate was $50 \mathrm{~mm} / \mathrm{min}$. Test was conducted according to PN-EN ISO 527-1:2020-01.

Charpy impact tests were carried out on unnotched samples using a LIANGONG XJ 5Z impact hammer (Shandong, China) according to PN-EN ISO 179-2 using a $2 \mathrm{~J}$ hammer.

\section{Thermomechanical test}

Thermomechanical properties of PLA and PLA/CSF samples were tested with a dynamic mechanical analyzer type Q800 TA Instruments (New Castle, DE, US) according to PN-EN ISO 6721-1. The test samples were cuboid in shape with dimensions of $70 \mathrm{~mm} \times 10 \mathrm{~mm} \times 4 \mathrm{~mm}$. Thermal sweep was scheduled from $30{ }^{\circ} \mathrm{C}$ to $140{ }^{\circ} \mathrm{C}$ at a heating rate of $2{ }^{\circ} \mathrm{C} / \mathrm{min}$, with a strain frequency of $1 \mathrm{~Hz}$ and an amplitude of $15 \mu \mathrm{m}$.

\section{RESULTS}

Tensile strength of PLA was $66.7 \pm 2.3 \mathrm{MPa}$. It decreased by $29 \%$ to $47.2 \pm 2.9 \mathrm{MPa}$ in samples containing $10 \%$ stalk particles compared to samples with pure PLA, as shown in Figure 2. This is most likely due to the weak interfacial bonding between the CS stalk fiber (hydrophilic) and PLA plastic 


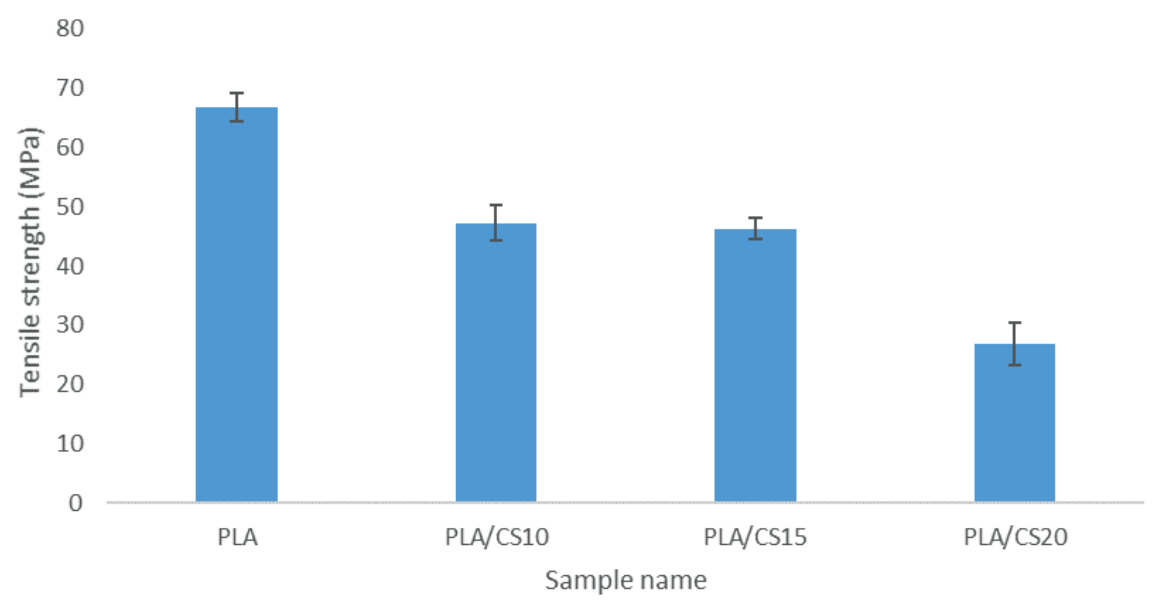

Fig. 2. Tensile strength comparison of PLA and biocomposite samples

(hydrophobic) $[27,28]$. It has been observed that increasing the proportion of stalks above $15 \%$ causes a drastic decrease in tensile strength. Previous studies also showed similar behavior in decreasing the tensile strength of PLA-based biocomposites reinforced with maize stalk particles with increasing maize straw fiber content $[23,29,30]$.

Tensile strain is a measure of the relative strain length of samples caused by the applied tensile force. At the maximum stress, the pure PLA samples had the highest strain as shown in Figure 3. The strain value of PLA samples was $3.42 \pm 0.17$ $\%$. Reduction in strain of fiber samples is due to poor interfacial adhesion between PLA and fiber [31]. The improvement of interfacial adhesion can be obtained by modifying the fiber surface $[27,28$, 32]. The CS can affect the interphase formation and mobility of polymers molecules in the composite. Short fibers cause the formation of aggregates which improve the strain especially at high composite loads [29]. Fiber due to its higher brittleness than PLA can influence the increase in the amount of brittle phase in composite and decrease in ductile phase by which the result can be decrease in strain $[33,34]$. The highest tensile strain at maximum load of samples containing maize stalk fibers was at $15 \%$ fiber proportion [29].

Figure 4 shows the Young's modulus values of tested materials. It can be seen that the modulus of elasticity or stiffness increases with the amount of fiber contribution. The stiffening effect results from the reduced mobility of the polymer chain due to the use of the CS fiber, which shows better mechanical properties compared to the polymer matrix [33] This observation is also noticeable when other fibers with polylactide matrix are used as observed by Nyambo [23, 35] among others. There was an increase in Young's modulus of $17 \%$, $9 \%$ and $28 \%$ relative to the matrix in the studied composites reinforced with 10,15 and $20 \%$ maize fiber. However, it was much less than in the study of Tarres et al. in which the matrix was HDPE [36].

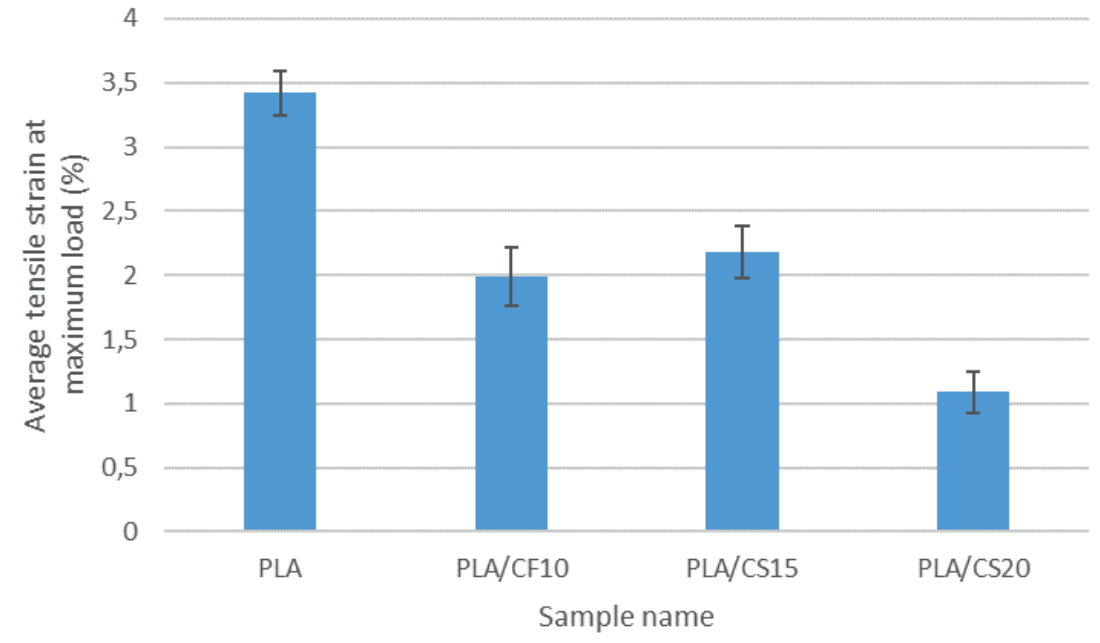

Fig. 3. Average tensile strain at maximum sample load 


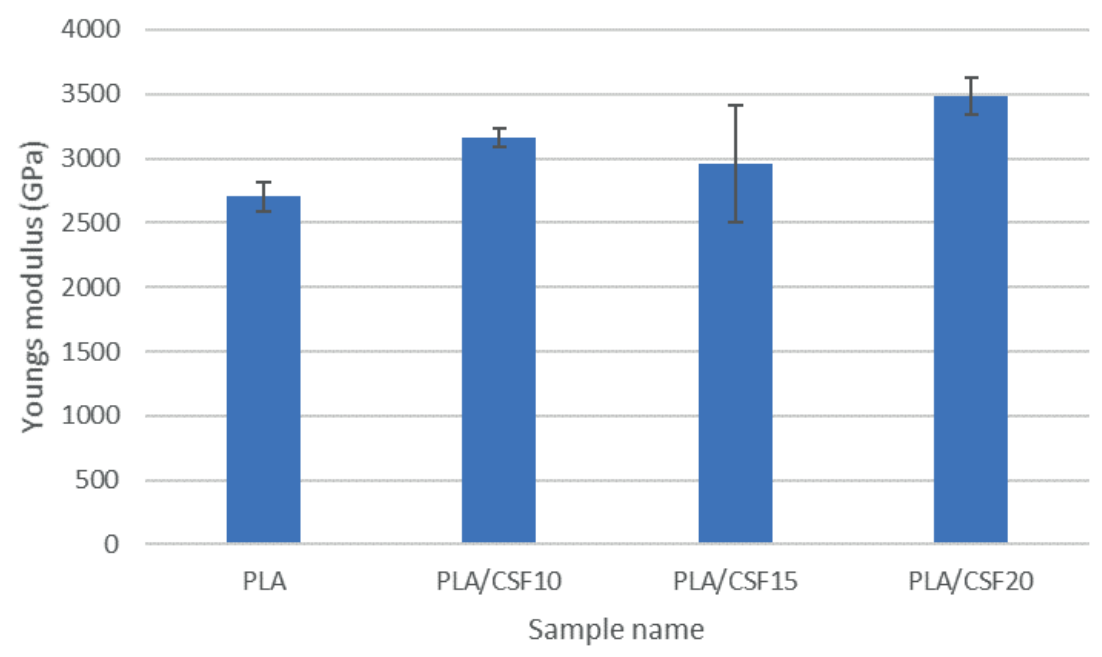

Fig. 4. Modulus of elasticity of tested materials

Figure 5 shows the average values of stress at break of the tested samples. The highest value of stress at break was recorded for the samples with pure PLA and its value was $61.59 \pm 3.75$ MPa. The addition of maize fiber to the polymer matrix decreased the stress at break. The stress values at $10 \%$ and $15 \%$ fiber content were very similar. This may be due to the PLA/CS15 composite having a higher proportion of fiber fraction less than $340 \mu \mathrm{m}$ in length than the PLA/CS10 composite, which transmit stress better [37]. On the other hand, above $15 \% \mathrm{CS}$ in the matrix, there is a noticeable strong decrease in stress related to poor material homogenization. A similar effect is noticed by Zhang et al [33].

Figure 6 shows the average values of strain at break of the tested samples. The samples with pure PLA had the highest strain and their strain value was $4.06 \pm 0.53 \%$. Addition of $10 \%$ maize stalk fiber to the PLA matrix reduced the strain at break by $51 \%$. The samples containing $15 \%$ had the highest strain among the biocomposites.

The PLA belongs to brittle polymers. It showed an average value of $22.31 \pm 1.51 \mathrm{~kJ} / \mathrm{m}^{2}$ when tested for impact strength. The addition of CS to the PLA matrix resulted in a linear decrease in impact strength with increasing fiber amount, from 19.4 $\pm 2.08 \mathrm{~kJ} / \mathrm{m}^{2}$ at $10 \%$ maize stalk fiber content up to $12.99 \pm 0.52 \mathrm{~kJ} / \mathrm{m}^{2}$ at $20 \%$ fiber content as shown in Figure 7. Decreased impact in the tested composites may be due to the stiffening effect of the matrix previously observed in the tensile test. Poor interfacial adhesion between the composite components results in poor stress transfer between them $[38,39,40]$. Furthermore, it is possible that an increase in CS content generates fiber clusters in biocomposites, which can function as crack initiation sites as is the case with wood fibers [41].

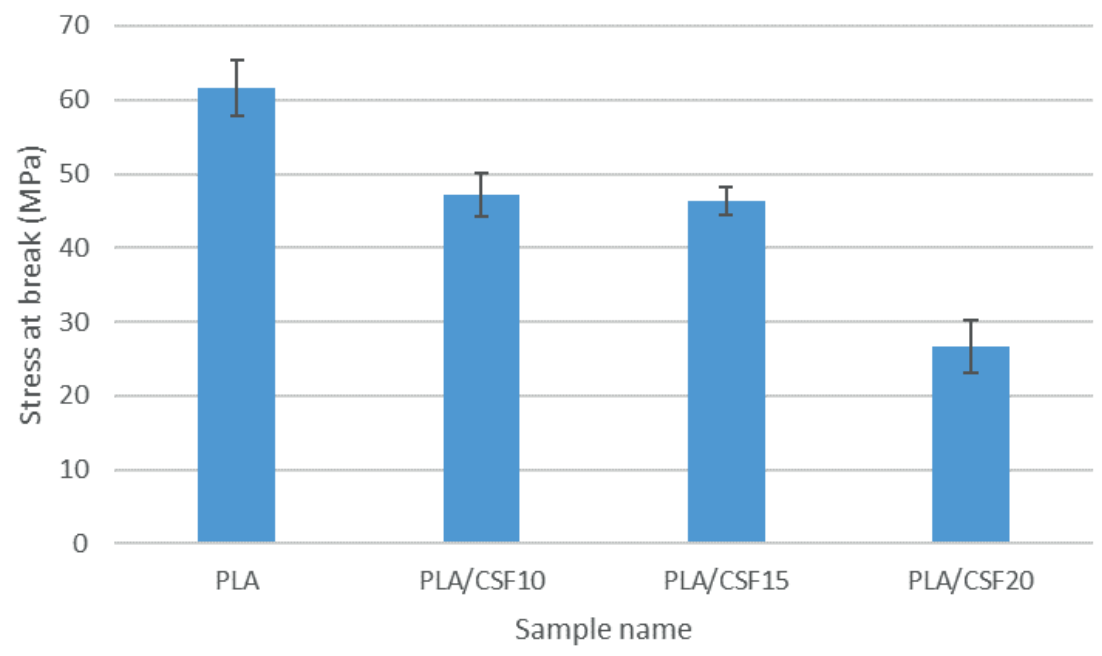

Fig. 5. Stress at break of tested samples 


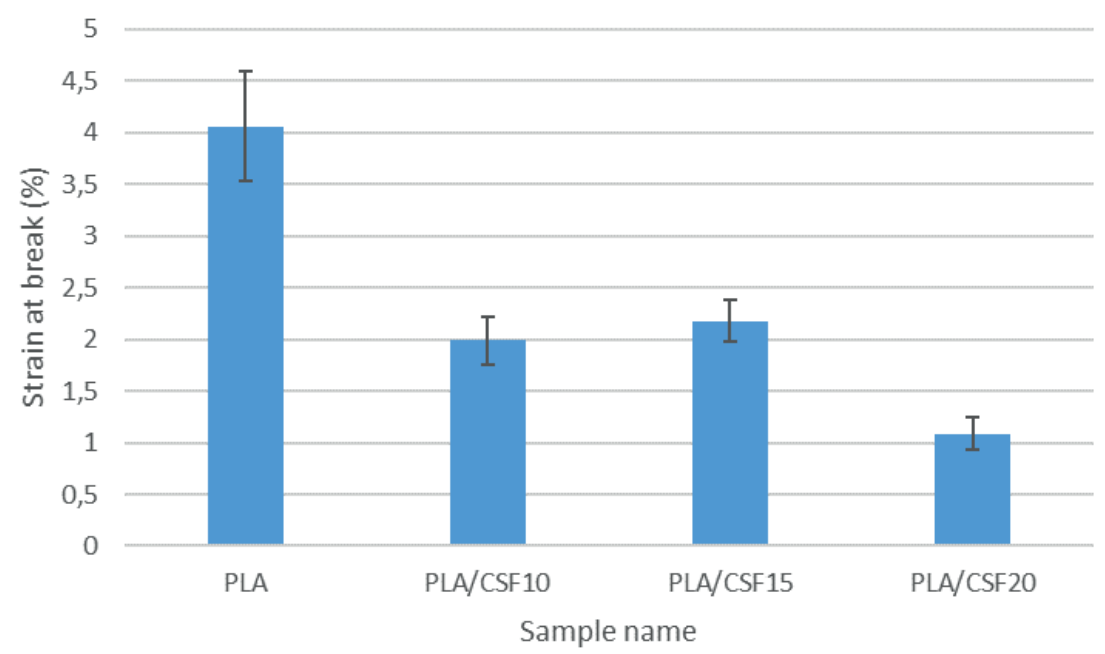

Fig. 6. Relative strain at break

Thermomechanical properties of tested samples were determined by the variation of damping factor $(\tan \delta)$ and the storage modulus $\left(E^{\prime}\right)$ as temperature function. Figure 9 shows the DMA thermomechanical curves. In Table 1 shows the values of $\mathrm{E}^{\prime}$ at $30^{\circ} \mathrm{C}, 50^{\circ} \mathrm{C}, 75^{\circ} \mathrm{C}, 130^{\circ} \mathrm{C}$ and the maximum value of Tan $\delta$ and the temperature at which this value is obtained. It can be seen that all composite samples showed higher $\mathrm{E}$ 'values than the pure polylactide sample. Especially at $30{ }^{\circ} \mathrm{C}$, where the storage modulus of pure PLA sample was $3380 \mathrm{MPa}$, and with the increasing amount of fiber in the matrix this E' increases up to 4111 $\mathrm{MPa}$ at $20 \% \mathrm{CS}$. The effect of increasing stiffness for polymer composites strengthened with natural filler has already been described elsewhere (42, 43). The effect of corn stalk strengthening is very evident beyond the glass transition area, where the value of modulus retained at $75{ }^{\circ} \mathrm{C}$ increased from 22.13 MPa without CS up to $65.65 \mathrm{MPa}$ with $15 \%$ corn fiber content. This effect may be due to the effect that relatively hard fillers have on the polymer matrix. The fillers also affect the change in G' value at $130{ }^{\circ} \mathrm{C}$ after cold crystallization. A twofold increase in modulus from 246 to $587.8 \mathrm{MPa}$ at $20 \%$ fiber content is evident compared to pure PLA.

$\operatorname{Tan} \delta$ is the quotient between $\mathrm{E}^{\prime \prime}$ and $\mathrm{E}^{\prime}$ (44). It is a ratio that determines the efficiency of energy loss of the material for molecular regrouping and internal friction (45). It can be seen in the graph that the maximum Tan $\delta$ value decreases along with the increase in CS. Which can be related to the increased stiffness imparted by the CS fibers. The addition of fibers hinders the molecular motion associated with damping and may be an advantage in some applications where better resistance to mechanical loading is required. The

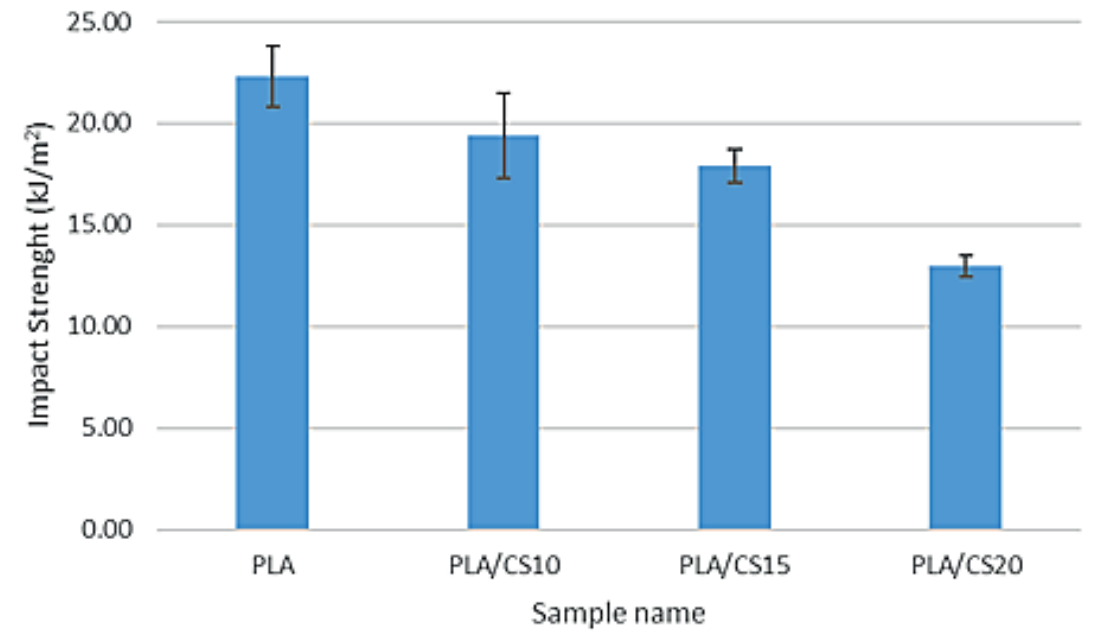

Fig. 7. Impact strength of tested samples 
Table 1. Variation of storage modulus E' at $30^{\circ} \mathrm{C}, 50{ }^{\circ} \mathrm{C}, 75^{\circ} \mathrm{C}, 130^{\circ} \mathrm{C}$ and Tan delta temperature dependence of the tested samples

\begin{tabular}{|c|c|c|c|c|c|}
\hline Composition symbol & $\mathrm{E}^{\prime} 30^{\circ} \mathrm{C}$ & $\mathrm{E}^{\prime} 50^{\circ} \mathrm{C}$ & $\mathrm{E}^{\prime} 75^{\circ} \mathrm{C}$ & $\mathrm{E}^{\prime} 130^{\circ} \mathrm{C}$ & Tan delta/ temperature \\
\hline $\mathrm{PLA}$ & $3380 \mathrm{MPa}$ & $3205 \mathrm{MPa}$ & $22.13 \mathrm{MPa}$ & $246.9 \mathrm{MPa}$ & $2.48 / 73.25^{\circ} \mathrm{C}$ \\
\hline $\mathrm{PLA} / \mathrm{CS} 10$ & $3648 \mathrm{MPa}$ & $3502 \mathrm{MPa}$ & $36.92 \mathrm{MPa}$ & $3112 \mathrm{MPa}$ & $1.72 / 72.41^{\circ} \mathrm{C}$ \\
\hline $\mathrm{PLA} / \mathrm{CS} 15$ & $3824 \mathrm{MPa}$ & $3659 \mathrm{MPa}$ & $64.65 \mathrm{MPa}$ & $3372 \mathrm{MPa}$ & $1.55 / 73.24^{\circ} \mathrm{C}$ \\
\hline $\mathrm{PLA} / \mathrm{CS} 20$ & $4111 \mathrm{MPa}$ & $3918 \mathrm{MPa}$ & $65.26 \mathrm{MPa}$ & $3382 \mathrm{MPa}$ & $1.23 / 71.33^{\circ} \mathrm{C}$ \\
\hline
\end{tabular}

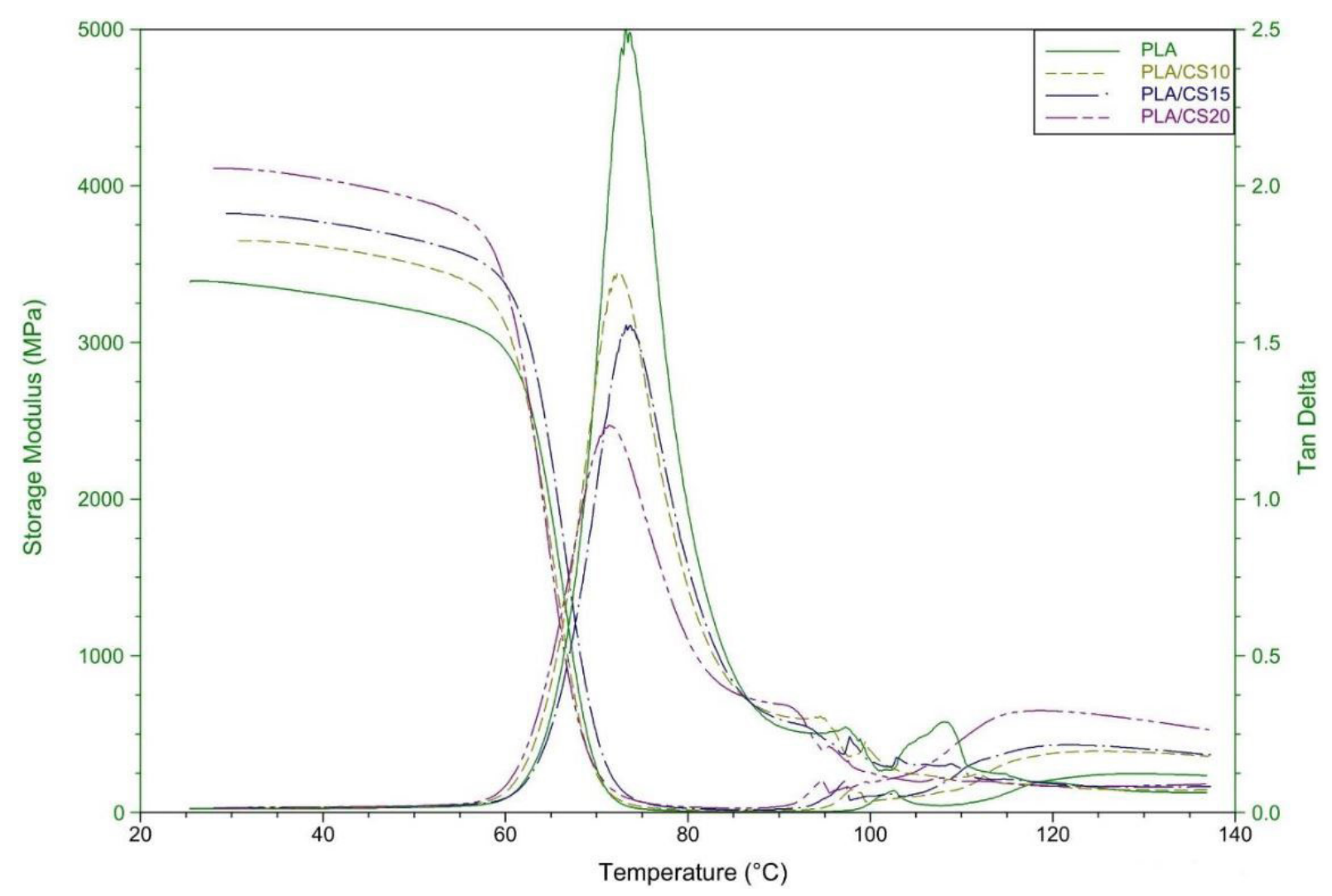

Fig. 8. The DMA thermomechanical curves of the tested samples

high temperature obtained for the sample containing $15 \%$ CS may indicate a better interfacial interaction between the composite components.

\section{CONCLUSIONS}

In the presented study, PLA-CS biocomposites (up to $20 \%$ CS by weight) were produced by extrusion followed by injection molding. The aim was to evaluate the effect of using long maize stalk fibers in the polylactide matrix on mechanical and thermomechanical properties. The CS is one of byproducts resulting from the cultivation of maize for grain. The poor interfacial interaction between the fiber and the polymer matrix caused the obtained composites to have poorer mechanical properties than pure polylactide. The CS caused a reduction in tensile strength from 29 to $40 \%$, strain at break from 47 to $73 \%$, stress at break from 23 to $57 \%$, and impact strength from 14 to $42 \%$. However, an improvement in modulus of elasticity of 10 to $25 \%$ as well as an improvement in retention modulus of 8 to $21 \%$ at $30{ }^{\circ} \mathrm{C}$ and 9 to $22 \%$ at $50{ }^{\circ} \mathrm{C}$ are noticeable.

From a mechanical point of view, the best fiber content was at $15 \%$ as it caused the least reduction in strain at break, stress at break, and strain at maximum stress relative to the polylactide matrix. The determined maize stalk fibers content in the composite will provide a reference value for further studies on the shredding process of maize fibers in terms of their use as fillers in polymer composites. 
This study shows that corn stalk (CS) fibers can be a good alternative to other lignocellulosic additives used in green composites. When used in green composites, corn stalks due to their very high availability and biodegradability allow for some economic and environmental benefits relevant to the closed loop plastics industry.

\section{REFERENCES}

1. Plastics Facts. 2020. An analysis of European plastics production, demand and waste data. Available: https://www.plasticseurope.org/application/ files/5716/0752/4286/AF_Plastics_the_factsWEB-2020-ING_FINAL.pdf [date accessed: 10 . Feb 2021].

2. Plastics - Facts 2019 An analysis of European plastics production, demand and waste data. Available: https://www.plasticseurope.org/application/ files/9715/7129/9584/FINAL_web_version_Plastics_the_facts2019_14102019.pdf [date accessed: 12. Feb 2021].

3. Rabnawaz M., Wyman I., Auras R., Cheng S. A roadmap towards green packaging: the current status and future outlook for polyesters in the packaging industry. Green Chemistry. 2017; 19(20): 4737-4753.

4. The New Plastics Economy: Rethinking the future of plastics. Available: https://www.ellenmacarthurfoundation.org/news/the-new-plastics-economy-rethinking-the-future-of-plastics-infographics [date accessed: 14. Feb 2021].

5. Zhu Y., Romain C., Williams C.K. Sustainable polymers from renewable resources. Nature. 2016: 540(7633): 354-362.

6. Dauvergne P. Why is the global governance of plastic failing the oceans?. Global Environmental Change. 2018; 51: 22-31.

7. Grabowska B. Polymer material biodegradation. Archives of Foundry Engineering. 2010; 10(2): 57-60.

8. Kale K., Deshmukh A.G., Dudhare M.S., Patil V.B. Microbial degradation of plastic: a review. Journal Of Biochemical Technology. 2015; 6(2): 952-961.

9. Leja K., Lewandowicz G. Polymer Biodegradation and Biodegradable Polymers - a Review. Polish Journal of Environmental Studies. 2010; 19(2): 255-266.

10. Lambert S., Wagner M. Environmental performance of bio-based and biodegradable plastics: the road Ahead. Chemical Society Reviews. 2017; 46(22): 6855-6871.

11. Haider T.P., Völker C., Kramm J., Landfester K., Wurm F.R. Plastics of the future? The impact of biodegradable polymers on the environment and on socjety. Angewandte Chemie. 2018; 58(1): 50-62.
12. Frącz W.J., Jankowski G., Bąk Ł. The Optimization of PHBV-hemp Fiber Biocomposite Manufacturing Process on the Selected Example. Advances in Science and Technology Research Journal. 2021; 15(2): 127-137

13. Market data bioplastics plastics. Available: https://www.european-bioplastics.org [date accessed: 03. Mar 2021]

14. Żakowska H. Bioplastics for food packaging production. Przemysł Spożywczy. 2018; 69(7): 26-30.

15. Gołębiewski J., Gibas E., Malinowski R. Selected biodegradable polymers - preparation, properties, applications. Polimery. 2018; 53(11-12): 799-807.

16. Mallet B., Lamnawar K., Maazouz A. Improvement of blown film extrusion of poly(lactic acid): structure-processing-properties relationships. Polymer Engineering \& Science. 2014; 54(4): 840-857.

17. Aniśko J., Barczewski M. Polylactide: from Synthesis and Modification to Final Properties. Advances in Science and Technology Research Journal. 2021; 15(3): 9-29.

18. Frone A.N., Berlioz S., Chailan J.F., Panaitescu D.M., Donescu D. Cellulose fiber-reinforced polylactic acid. Polymer Composites. 2011; 32(6): 976-985.

19. Auras R., Harte B., Selke S. An Overview of Polylactides as Packaging Materials. Macromolecular Bioscience. 2004; 4(9): 835-864.

20. Van Velzen E.T., Jansen M., Brouwer M.T., Feil A., Molenveld K., Pretz T. Efficiency of recycling post-consumer plastic packages. In 32 International Conference of the Polymer Processing Society, Lyon, France 2017.

21. Lasprilla A.J.R., Martinez G.A.R., Lunelli B.H., Jardini A.L., Filho R.M. Polylactic acid synthesis for application in biomedical devices - a review. Biotechnology Advances. 2012; 30(1): 321-328.

22. Kaisangsri N., Kerdchoechuen O., Laohakunjit N. Biodegradable foam tray from cassava starch blended with natural fiber and chitosan. Industrial Crops and Products. 2012; 37(1): 542-546.

23. Nyambo C., Mohanty A.K., Misra M. Polylactidebased renewable green composites from agricultural residues and their hybrids Biomacromolecules. 2010; 11(6): 1654-1660.

24. Dicker M.P., Duckworth P.F., Baker A.B., Francois G., Hazzard M.K., Weaver P.M. Green composites: a review of material attributes and complementary applications. Composites Part A: Applied Science and Manufacturing. 2014; 56(1): 280-289.

25. Ku H., Wang H., Pattarachaiyakoop N., Trada M. A review on the tensile properties of natural fiber reinforced polymer composites. Composites Part B: Engineering. 2011; 42(11): 856-873.

26. Moraczewski K., Malinowski R., Łączny D., Macko M. Surface modification of maize stem with 
polydopamine and tannic acid coatings. Surfaces and Interfaces. 2021; 26: 1013-1019.

27. Luo H., Xiong G., Ma Ch., Chang P., Yao F., Zhu Y., Zhang Ch., Wan Y. Mechanical and thermomechanical behaviors of sizingtreated corn fiber/ polylactide composites. Polymer Testing. 2014; 39(10): 45-52.

28. Luo H., Zhang Ch., Xiong G. Effects of alkali and alkali/silane treatments of corn fibers on mechanical and thermal properties of its composites with polylactic acid. Polymer composites. 2015; 37(12): 3499-3507.

29. Zhang P., Wang B., Gao D., Wen L. The Study on the Mechanical Properties of Poly(lactic acid)/ Straw Fiber Composites. Applied Mechanics and Materials. 2012; 200(1): 312-315.

30. Faludi G., Dora G., Imre B., Renner K., Móczó J., Pukánszky B. PLA/lignocellulosic fiber composites: Particle characteristics, interfacial adhesion, and failure mechanism Journal of Applied Polymer Science. 2013; 131(4).

31. Kumar A., Jyske T., Möttönen V. Properties of Injection Molded Biocomposites Reinforced with Wood Particles of Short-Rotation Aspen and Willow. Polymers. 2020; 12(2).

32. Luo H., Yang Z., Yao F., Li W., Wan Y. Improved properties of corn fiber-reinforced polylactide composites by incorporating silica nanoparticles at interfaces. Polymers and Polymer Composites. 2020; 28(3): 170-179.

33. Zhang K., He Y., Zhang H., Li H. Research on mechanical properties of corn stalk. AIP Conference Proceedings. 2017; 1820(1).

34. Rodríguez M., Rodríguez A., Bayer J.R., Vilaseca F., Gironès J., Mutjé P. Determination of corn stalk fibers' strength through modeling of the mechanical properties of its composites. Bioresources. 2010; 5(4): 2535-2546.

35. Shibata M., Ozawa K., Teramoto N., Yosomiya R. Biocomposites Made from Short Abaca Fiber and Biodegradable Polyesters. Macromolecular Materials and Engineering. 2003; 288(1): 35-43.
36. Tarrés Q., Hernández-Díaz D., Ardanuy M. Interface Strength and Fiber Content Influence on Corn Stover Fibers Reinforced Bio-Polyethylene Composites Stiffness. Polymers. 2021; 13(5).

37. Tarrés Q., Ardanuy M. Evolution of Interfacial Shear Strength and Mean Intrinsic Single Strength in Biobased Composites from Bio-Polyethylene and Thermo-Mechanical Pulp-Corn Stover Fibers. Polymers. 2020; 12(6).

38. Keener T.J., Stuart R.K., Brown T.K. Maleated coupling agents for natural fibre composites. Composites Part A: Applied Science and Manufacturing. 2004; 35(3): 357-362.

39. Lu J.Z., Wu Q., McNabb H.S. Chemical coupling in wood fiber and polymer composites: A review of coupling agents and treatments. Wood Fiber Science. 2000 ; 32(1): 88-104.

40. Lu J.Z., Wu Q., Negulescu I.I. The influence of maleation on polymer adsorption and fixation, wood surface wettability, and interfacial bonding strength in wood-PVC composites. Wood Fiber Science. 2002; 34(1): 434-459,

41. Sohn J.S., Cha S.W. Effect of chemical modification on mechanical properties of wood-plastic composite injection-molded parts. Polymers. 2018; 10(12).

42. Quiles-Carrillo L., Montanes N., Sammon C., Balart R., Torres-Giner S. Compatibilization of highly sustainable polylactide/almond shell flour composites by reactive extrusion with maleinized linseed oil. Industrial Crops and Products. 2018; 111(1): 878-888.

43. Aguero A., Quiles-Carrillo L., Jorda-Vilaplana A., Fenollar O., Montanes N. Effect of different compatibilizers on environmentally friendly composites from poly(lactic acid) and diatomaceous earth. Polymer. 2019; 68(5): 893-903.

44. Saba N., Jawaid M., Alothman O. Y., Paridah M. T. A review on dynamic mechanical properties of natural fibre reinforced polymer composites. Construction and Building Materials. 2016; 106(1): 149-159.

45. Arputhabalan J., Palanikumar K. Tensile properties of natural fiber reinforced polymers: An overview. Applied Mechanics and Materials. 2015; 766(1): 133-139. 